\title{
Stability Testing of Beclomethasone Dipropionate Nanoemulsion
}

\author{
Mohammad Sarfaraz Alam, Mohammad Sajid Ali*, Mohammad Intakhab Alam, \\ Tarique Anwer and Mohammed Mohsen A Safhi \\ College of Pharmacy, Jazan University, Jazan, Saudi Arabia
}

*For correspondence: Email: mdsajidaali@gmail.com; Tel: +966591668359

Received: 23 February 2014

Revised accepted: 15 November 2014

\begin{abstract}
Purpose: To perform stability studies on a nanoemulsion formulation containing beclomethasone dipropionate $(B D)$ and prepared by spontaneous emulsification method.

Method: A nanoemulsion (o/w) containing BD was prepared using eucalyptus oil, Tween-40, ethanol and distilled water. The nanoemulsions were characterized by droplet size, $\mathrm{pH}$, viscosity, conductivity and refractive index. Stability studies were performed according to International Council on Harmonization (ICH) guidelines over a period of 3 months. Droplet size, $\mathrm{pH}$, viscosity, conductivity and refractive index were determined monthly for 3 months. The shelf-life of the nanoemulsion formulation was determined by accelerated stability testing.

Results: The droplet size, conductivity, viscosity, $\mathrm{pH}$ and refractive index of the optimized formulations did not change significantly $(p \geq 0.05)$ after 3 months of storage at room temperature $\left(25^{\circ} \mathrm{C}\right)$. The shelf life was 1.83 years at room temperature.

Conclusion: The study demonstrates that the physical and chemical stability of BD is enhanced when it is formulated as a nanoemulsion.
\end{abstract}

Keywords: Nanoemulsion, Beclomethasone dipropionate, Shelf-life, Accelerated stability, Viscosity, Conductivity, Refractive index

Tropical Journal of Pharmaceutical Research is indexed by Science Citation Index (SciSearch), Scopus, International Pharmaceutical Abstract, Chemical Abstracts, Embase, Index Copernicus, EBSCO, African Index Medicus, JournalSeek, Journal Citation Reports/Science Edition, Directory of Open Access Journals (DOAJ), African Journal Online, Bioline International, Open-J-Gate and Pharmacy Abstracts

\section{INTRODUCTION}

Stability study under normal storage conditions is an effective way to determine the consistent quality of a dosage form; however, storage time is a major factor. The stability of an emulsion is concerned with the maintenance of internal phase dispersion in the external phase without effective changes in both phases. In other words, the system should maintain the same number and size of the dispersed droplets in the dispersion medium. To generate stability data in a fast and reliable manner, accelerated stability studies are carried out. Measuring the physicochemical properties of a product under accelerated conditions can reflect the performance of the product over time.

Chemically, a change in $\mathrm{pH}$ of the formulation can indicate a degradation or ionization of one or more of the ingredients in the formulation. Furthermore, chemical transformation of ingredients reflects their incompatibility or degradation which in turn can lead to toxic effects in consumers. Any inversion in the system (ON to W/O or vice versa) can be identified by measurement of conductivity. Droplet size measurement is an important factor in assessing the stability of emulsion systems. Change in droplet size with time is usually as a 
result of the aggregation and coalescence of the internal phase droplets to form larger droplets [1]. A decrease in viscosity with time points to a kinetically unstable emulsion where the possibility is high that freely moving droplets would collide with each other and coalesce.

Hence, detection of viscosity change with time can provide data about system stability [2].

Beclomethasone dipropionate is a highly potent glucocorticoid receptor agonist which possesses immunosuppressive, anti-inflammatory, and antiproliferative properties. It is used topically as well as systemically in the treatment of psoriasis. It exerts its action by inhibition of phospholipase A2 which leads to the inhibition of synthesis of arachidonic acid and controls the biosynthesis of prostaglandins and leukotrienes [3]. However, BD has poor permeability through skin which reduces its therapeutic effectiveness at the target site.

In recent years, much attention has been focused on lipid-based formulations to improve the permeability and bioavailability of poor water soluble drug compounds. An attempt was made to use natural oils such as eucalyptus oil which act as a vehicle as well as penetration enhancer in nanoemulsions. Nanoemulsions are thermodynamically stable, transparent dispersions of oil and water stabilized by an interfacial film of surfactant and co-surfactant molecules having a droplet size of $10-200 \mathrm{~nm}$ [4-6]. Nanoemulsions have been known to increase therapeutic efficacy of many drugs as well as enhance the physical and chemical stability of many drugs [7].

The aim of the present study was to evaluate the stability of O/W nanoemulsion containing BD, including evidence of how the quality of $\mathrm{O}$ W nanoemulsion containing $B D$ changes with time under the influence of environmental factors (temperature, humidity and light) that can alter its shelf-life.

\section{EXPERIMENTAL}

\section{Materials}

Beclomethasone dipropionate was obtained as a gift from Gaurav Pharma Limited (Delhi, India)., eucalyptus oil was obtained from Scientific International (New Delhi, India), Tween-40, pleurol oleic, glycol, Brij-35, propanol, isopropyl alcohol and ethanol were purchased from Merck (Merck, India). Labrasol, Safsol and Capryol were obtained as gifts from Gattefosse (Mumbai,
India). All other chemicals used were of analytical grade.

\section{Preparation of BD nanoemulsion}

Nanoemulsions of BD were prepared by spontaneous emulsification method. Optimized nanoemulsion was prepared by dissolving 0.025 $\%(w / v)$ of BD in $10 \%(v / v)$ eucalyptus oil then $34 \%(\mathrm{v} / \mathrm{v})$ mixture of Tween-40 and ethyl alcohol $(1: 1 \mathrm{v} / \mathrm{v})$ were added slowly in oil phase. The remaining amount of distilled water was added slowly to get the final preparation of $100 \%(\mathrm{v} / \mathrm{v})$.

\section{Characterization of nanoemulsion}

\section{Size and size distribution}

Droplet size and its distribution was determined by photon correlation spectroscopy (PCS), using a Zetasizer $1000 \mathrm{HS}$ (Malvern Instruments, UK). Light scattering was monitored at $25{ }^{\circ} \mathrm{C}$ at a scattering angle of $90^{\circ}$.

\section{Viscosity}

The viscosity of the nanoemulsion was determined using Brookfield DV III ultra V6.0 RV cone and plate rheometer (Brookfield Engineering Laboratories, Inc, Middleboro, MA) using spindle \# CPE40 at $25 \pm 0.3^{\circ} \mathrm{C}$.

\section{Refractive index}

Refractive index (RI) of nanoemulsion formulation was determined using an Abbes type refractrometer (Precision Standard Testing Equipment Corporation, India) [8].

\section{$\mathrm{pH}$ of nanoemulsion}

Measurement of $\mathrm{pH}$ of the samples was made by using the pH-meter (Cyberscan, Eutech Instrument, Singapore). The pH-meter was calibrated before each measurement of $\mathrm{pH}$ of the nanoemulsion. The $\mathrm{pH}$-reading was recorded after transferring the samples into a beaker and the $\mathrm{pH}$-meter probe was immersed into it. The $\mathrm{pH}$ of the freshly prepared formulations was measured and used to compare the changes in $\mathrm{pH}$ of the formulations after specific time intervals at different temperatures.

\section{Conductivity}

The conductivity was measured using a conductometer (Cyberscan, Eutech Instrument, Singapore). The sample (2 g) was transferred into a beaker and the conductometer probe was immersed into it. The conductivity reading in $\mu s$ 
was recorded. Conductivity of freshly prepared formulations was measured and compared with changes in conductivity of the formulations after specified time intervals at different temperatures [9].

\section{Stability studies}

Stability studies were performed on the optimized BD-nanoemulsion to assess their physical and chemical stabilities. Samples were stored in sealed glass vials $(10 \mathrm{ml})$ for a period of 3 months. It was performed by keeping the samples at different storage conditions of temperature including refrigerator temperature (4 $\left.{ }^{\circ} \mathrm{C}\right)$, room temperature $\left(25^{\circ} \mathrm{C}\right)$ and $40{ }^{\circ} \mathrm{C}$. The droplet size, viscosity, $\mathrm{pH}$, conductivity and refractive index were determined at $0,1,2$ and 3 months. BD-nanoemulsion was also subjected to the accelerated stability studies. Three batches of optimized formulation were taken in glass vials and were kept at accelerated temperatures of 30 , 40,50 and $60{ }^{\circ} \mathrm{C}$ at ambient humidity. The samples were withdrawn at regular intervals of 0 , 1,2 and 3 months and assessed for BD content [10]. These samples were analyzed for drug content by stability indicating HPLC method at a wavelength of $254 \mathrm{~nm}$.

The amount of drug decomposed and the amount remaining (undecomposed drug) at each time interval was calculated. Order of degradation was determined by the graphical method. Degradation rate constant $(\mathrm{K})$ was determined at each temperature. Arrhenius plot was constructed between $\log K$ and $1 / T$ to determine the shelf-life of optimized nanoemulsion formulation. The degradation rate constant at $25{ }^{\circ} \mathrm{C} \quad\left(\mathrm{K}_{25}\right)$ was determined by extrapolating from Arrhenius plot. The shelf-life $\left(T_{0.9}\right)$ of the formulation was determined using $\mathrm{Eq}$ 1.

Shelf life $=0.1052 / \mathrm{K}$

where $\mathrm{K}$ is the degradation rate constant.

\section{Beclomethasone dipropionate (BD) analysis}

A new, simple, specific, sensitive, rapid, accurate and precise RP-HPLC method was developed for the estimation of $\mathrm{BD}$ in nanoemulsion formulation. Nanoemulsions were chromatographed on a reverse phase $\mathrm{C} 18$ column $(25 \mathrm{~cm} \times 4.6 \mathrm{~mm}, 5 \mu)$ in a mobile phase consisting of methanol and water in the ratio $70: 30 \mathrm{v} / \mathrm{v}$. The mobile phase was pumped at a flow rate of $1.0 \mathrm{~mL} / \mathrm{min}$ with detection at $254 \mathrm{~nm}$. The detector response was linear in the concentration of $10-100 \mu \mathrm{g} / \mathrm{mL}$ for BD. The limit of detection (LOD) and limit of quantification (LOQ) were 1.5661 and $0.6664 \mu \mathrm{g} / \mathrm{mL}$, respectively. The intra and inter day variation was less than $1 \%$ while the retention time was $3.20 \mathrm{~min}$. The method was employed to determine the concentration of $\mathrm{BD}$ in nanoemulsion formulations at various elevated temperatures. Furthermore, pure eucalyptus oil, surfactant, co-surfactant and water were run separately to check interference of the excipients used in the formulations [11].

\section{Statistical analysis}

Statistical analysis was performed by the oneway analysis of variance (ANOVA) followed by Tukey-Kramer multiple comparisons test using Graph Pad Instat software (GraphPad Software Inc., CA, USA) to determine difference of all the parameters studied at the initial and after 90days of observation and at all storage conditions. Differences were considered significant at $p<$ 0.05 .

\section{RESULTS}

The results of the changes in the physicochemical properties of the nanoemulsions are shown in Table 1. Following storage for 3 months at refrigerator temperature $\left(4{ }^{\circ} \mathrm{C}\right)$, room temperature $\left(25^{\circ} \mathrm{C}\right)$ and $40^{\circ} \mathrm{C}$, changes in the values of these parameters were not statistically significant $(p<0.05)$.

The degraded and remaining amount of $\mathrm{BD}$ at different temperatures are shown in Table 2 . The percent drug remaining was found to be more than $90 \%$ during the storage period at different temperatures. The order of degradation was determined by graphical method at each temperature. The order of degradation was first order (Figure 1). The rate of degradation is directly proportional to the first power of the concentration of a single reactant in first order degradation. The correlation coefficients of first order degradation as well as zero order degradation were determined at each temperature as shown in Figures 1 and 2. Therefore for first order degradation, log $\%$ of drug remaining was plotted against time (Figure 1) and $K$ was calculated from the slope of the curve at each temperature using Eq 2.

Slope $=-K / 2.303$

where $\mathrm{K}$ is the degradation rate constant. 
Table 1: Droplet size, viscosity, RI, and conductivity of optimized nanoemulsion during storage

\begin{tabular}{|c|c|c|c|c|c|c|}
\hline $\begin{array}{l}\text { Time } \\
\text { (month) }\end{array}$ & $\operatorname{Temp}\left({ }^{\circ} \mathrm{C}\right)$ & $\begin{array}{c}\text { Mean droplet } \\
\text { size }(n m) \pm S D \\
(n=3)\end{array}$ & $\begin{array}{c}\text { Mean } \\
\text { Viscosity } \\
(m P) \pm S D \\
(n=3)\end{array}$ & $R I \pm S D(n=3)$ & $\mathrm{pH}$ & $\begin{array}{c}\text { Conductivity } \\
(\mu \mathrm{s}) \pm S D\end{array}$ \\
\hline 0 & $4.0 \pm 0.5$ & $90.30 \pm 0.73$ & $28.45 \pm 1.02$ & $1.409 \pm 0.031$ & $5.91 \pm 0.013$ & $348 \pm 2.31$ \\
\hline 1 & $4.0 \pm 0.5$ & $90.33 \pm 0.42$ & $28.37 \pm 1.01$ & $1.410 \pm 0.022$ & $5.72 \pm 0.028$ & $345 \pm 2.01$ \\
\hline 2 & $4.0 \pm 0.5$ & $90.83 \pm 0.83$ & $28.34 \pm 1.03$ & $1.414 \pm 0.023$ & $5.71 \pm 0.025$ & $350 \pm 2.11$ \\
\hline 3 & $4.0 \pm 0.5$ & $90.99 \pm 1.09$ & $28.09 \pm 1.01$ & $1.416 \pm 0.027$ & $5.69 \pm 0.021$ & $351 \pm 2.22$ \\
\hline 0 & $25 \pm 0.5$ & $90.30 \pm 0.73$ & $28.45 \pm 1.02$ & $1.409 \pm 0.023$ & $5.91 \pm 0.013$ & $348 \pm 2.31$ \\
\hline 1 & $25 \pm 0.5$ & $90.49 \pm 0.93$ & $28.41 \pm 1.11$ & $1.412 \pm 0.028$ & $5.69 \pm 0.025$ & $347 \pm 2.37$ \\
\hline 2 & $25 \pm 0.5$ & $90.27 \pm 0.31$ & $28.27 \pm 1.39$ & $1.417 \pm 0.025$ & $5.61 \pm 0.035$ & $351 \pm 2.51$ \\
\hline 3 & $25 \pm 0.5$ & $90.96 \pm 0.47$ & $28.03 \pm 1.07$ & $1.419 \pm 0.021$ & $5.53 \pm 0.027$ & $353 \pm 2.32$ \\
\hline 0 & $40 \pm 0.5$ & $90.30 \pm 0.73$ & $28.45 \pm 1.02$ & $1.409 \pm 0.023$ & $5.91 \pm 0.013$ & $348 \pm 2.31$ \\
\hline 1 & $40 \pm 0.5$ & $90.41 \pm 0.63$ & $28.21 \pm 1.21$ & $1.414 \pm 0.029$ & $5.69 \pm 0.015$ & $350 \pm 2.37$ \\
\hline 2 & $40 \pm 0.5$ & $90.31 \pm 0.17$ & $28.17 \pm 1.09$ & $1.419 \pm 0.045$ & $5.51 \pm 0.005$ & $350 \pm 1.11$ \\
\hline 3 & $40 \pm 0.5$ & $91.21 \pm 0.69$ & $27.89 \pm 1.30$ & $1.424 \pm 0.091$ & $5.43 \pm 0.017$ & $355 \pm 1.92$ \\
\hline
\end{tabular}

Table 2: Degradation of optimized nanoemulsion

\begin{tabular}{lccccc}
\hline $\begin{array}{l}\text { Time } \\
(\text { day) }\end{array}$ & $\begin{array}{c}\text { Temperature } \\
\left({ }^{\circ} \mathbf{C}\right)\end{array}$ & $\begin{array}{c}\text { Drug } \\
\text { content } \\
(\mathbf{m g})\end{array}$ & $\begin{array}{c}\text { Drug degraded } \\
(\mathbf{m g})\end{array}$ & $\begin{array}{c}\text { Drug } \\
\text { remaining (\%) }\end{array}$ & $\begin{array}{c}\text { Log \% drug } \\
\text { remaining }\end{array}$ \\
\hline 0 & $30 \pm 0.5$ & 5 & 0.029 & 100 & \\
30 & $30 \pm 0.5$ & 4.971 & 0.02 & 1.997 \\
60 & $30 \pm 0.5$ & 4.916 & 0.084 & 98.32 & 1.9927 \\
90 & $30 \pm 0.5$ & 4.838 & 0.162 & 96.76 & 1.989 \\
0 & $40 \pm 0.5$ & 5 & 0 & 100 & 2 \\
30 & $40 \pm 0.5$ & 4.975 & 0.025 & 99.5 & 1.995 \\
60 & $40 \pm 0.5$ & 4.881 & 0.119 & 97.62 & 1.989 \\
90 & $40 \pm 0.5$ & 4.778 & 0.222 & 95.56 & 1.985 \\
0 & $50 \pm 0.5$ & 5 & 0 & 100 & 2 \\
30 & $50 \pm 0.5$ & 4.951 & 0.049 & 99.02 & 1.992 \\
60 & $50 \pm 0.5$ & 4.86 & 0.14 & 97.2 & 1.985 \\
90 & $50 \pm 0.5$ & 4.731 & 0.269 & 94.62 & 1.979 \\
0 & $60 \pm 0.5$ & 5 & 0 & 100 & 2 \\
30 & $60 \pm 0.5$ & 4.911 & 0.089 & 98.22 & 1.992 \\
60 & $60 \pm 0.5$ & 4.824 & 0.176 & 96.48 & 1.984 \\
90 & $60 \pm 0.5$ & 4.731 & 0.269 & 94.62 & 1.975 \\
\hline
\end{tabular}

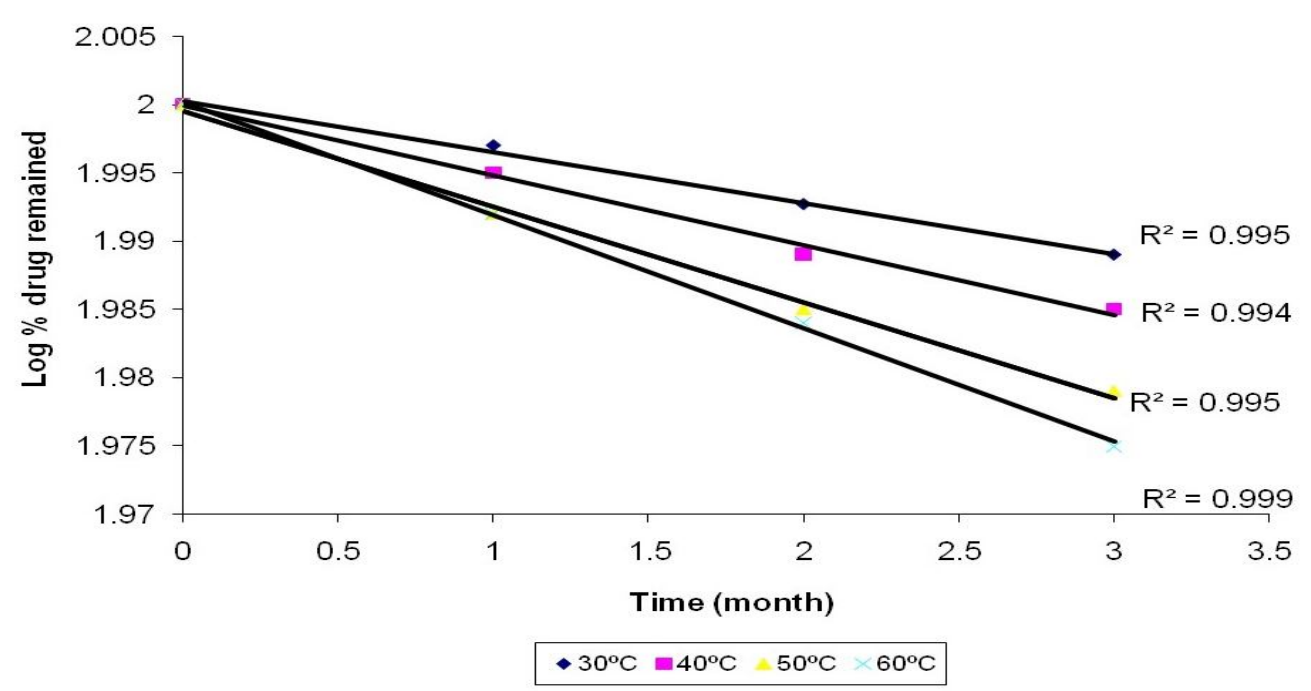

Figure 1: First order degradation kinetics of BD from optimized nanoemulsion at different temperatures 


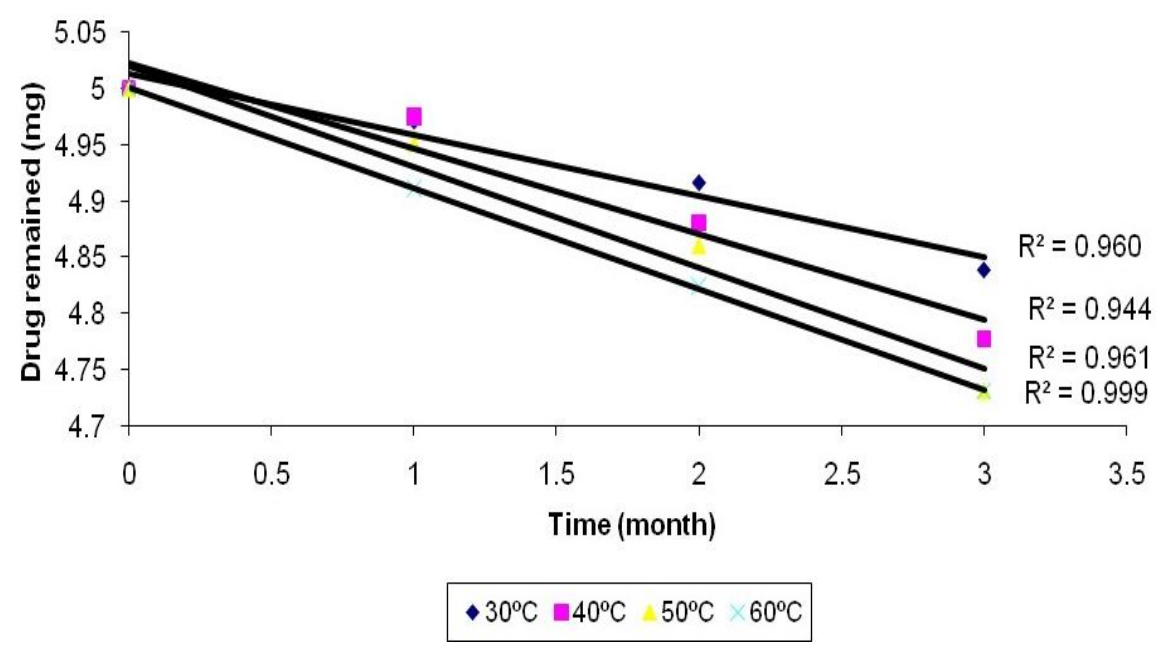

Figure 2: Zero order degradation kinetics of BD from optimized nanoemulsion at different temperatures

Table 3: Accelerated stability data for optimized nanoemulsion at $25^{\circ} \mathrm{C}$

\begin{tabular}{lccccc}
\hline $\begin{array}{l}\text { Temperature } \\
\left({ }^{\circ} \mathbf{C}\right)\end{array}$ & Slope & $\begin{array}{c}\mathbf{K} \\
\left(\mathbf{m o n t h}^{-1}\right)\end{array}$ & Log K & $\begin{array}{c}\text { Absolute } \\
\text { temperature (T) }\end{array}$ & $\mathbf{1 / T}^{\mathbf{2}} \mathbf{1 0}^{\mathbf{3}}$ \\
\hline 30 & -0.003 & 0.006909 & -2.16058 & 303 & 3.30033 \\
40 & -0.005 & 0.011515 & -1.93874 & 313 & 3.19488 \\
50 & -0.007 & 0.016121 & -1.79261 & 323 & 3.09597 \\
60 & -0.008 & 0.018424 & -1.73462 & 333 & 3.00300 \\
25 & & 0.004771 & -2.32135 & 298 & 3.35570 \\
\hline
\end{tabular}

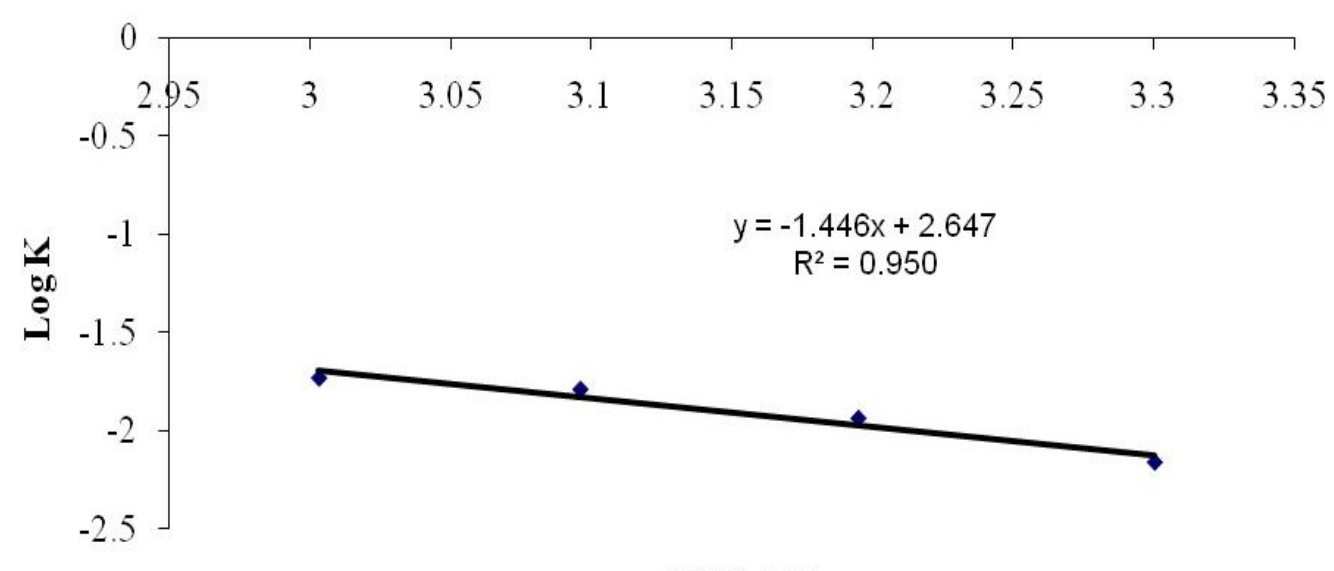

$1 / T \times 10^{3}$

Figure 3: Arrhenius plot between Log $\mathrm{K}$ and 1/T for optimized nanoemulsion

The values of $\mathrm{K}$ at each temperature are given in the Table 3. The log of drug remaining was plotted against time (months). Slope of each line was obtained and $\mathrm{K}$ was calculated by the formula. The effect of temperature on the degradation was studied by plotting log $\mathrm{K} v / \mathrm{s} 1 / \mathrm{T}$. (Figure 3). The value of $\mathrm{K}$ at $25^{\circ} \mathrm{C}\left(\mathrm{K}_{25}\right)$ was obtained by extrapolation of the plot and shelf-life was then calculated. The shelf-life of optimized nanoemulsion formulation was 1.83 years.

\section{DISCUSSION}

An ideal drug product must be stable throughout the intended shelf-life period. Stability is one of the problems associated with the development of dosage form. Stability of nanoemulsions refers to the physical and chemical integrity and protection against microbial contamination [12,13]. Therefore the optimized nanoemulsion formulations were subjected to stability studies at 
varying temperatures for 3-months to evaluate the potential to prevent the degradation of BD.

The changes in these parameters were not statistically significant $(p<0.05)$. These results indicated that the optimized formulation was stable as there were no significant changes in physical parameters (droplet size, viscosity, $\mathrm{pH}$, conductivity and $\mathrm{RI}$ ). The degradation of $\mathrm{BD}$ was very slow at each temperature which indicates the chemical stability of BD in the nanoemulsion formulation. Thus, the optimized nanoemulsion was stable chemically as well as physically.

The degraded and remaining amount of BD at different temperatures for three months exhibited insignificant changes in the result. It exhibited more than $90 \%$ of $\mathrm{BD}$ retained in the dosage form even after the three months of storage period. Drugs in a dosage forms are considered to be stable if they retained $\geq 90 \%$ of the initial drug concentration [14]. It indicates the stability of the dosage form over the intended period of time. Instability in liquid dosage forms is primarily due to interactions between the drug substance and the excipients and degradation of the active pharmaceutical ingredient by usual degradation routes including oxidation, hydrolysis, photolysis and thermolysis. The low concentration of BD degraded demonstrates the low risk of instability associated with the dosage form investigated.

\section{CONCLUSION}

The developed nanoemulsion is stable against creaming, coalescence, phase separation and Ostwald ripening. The BD shows very low solubility in the aqueous phase of the $\mathrm{O} W$ nanoemulsion. Furthermore, the combination of non-ionic surfactants used produces a highly stable nanoemulsion. The physical stability of the nanoemulsion was also good. The shelf-life of the developed nanoemulsion formulation is 1.83 years at room temperature $\left(25^{\circ} \mathrm{C}\right)$.

\section{REFERENCES}

1. Petsev D, Denkov N, Kralchevsky P. Flocculation of deformable emulsion droplets. J Colloid Interface Sci 1995; 176: 201-213.
2. Badolato GG, Aguilar F, Schuchmann HP, Sobisch T, Lerche $D$. Evaluation of long term stability of model emulsions by multisample analytical centrifugation. Prog Colloid Polym Sci 2008; 134: 66-73.

3. Christophers E. Psoriasis-epidemiology and clinical spectrum. Clin Exp Dermatol 2001; 26: 314-320.

4. Azeem A, Rizwan M, Ahmad FJ, lqbal Z, Khar RK, Aqil M, Talegaonkar S. Nanoemulsion components screening and selection: A technical note. AAPS PharmSciTech 2009; 10(1): 69-76.

5. Baboota S, Shakeel F, Ahuja A, Ali J, Shafiq S. Design development and evaluation of novel nanoemulsions formulations for transdermal potential of celecoxib. Acta Pharm 2007a; 8: 316-332.

6. Shakeel F, Shafiq S, Haq N, Alanazi FK, Alsarra IA. Nanoemulsions as potential vehicles for transdermal and dermal delivery of hydrophobic compounds: an overview. Expert Opin Drug Deliv 2012; 9(8): 953974.

7. Taylor P. Ostwald ripening in emulsions. Adv Colloid Interface Sci 1998; 75: 107-163.

8. Baboota S, Alam MS, Sharma S, Sahni JK, Kumar A, Ali J. Nanocarrier-based hydrogel of betamethasone dipropionate and salicylic acid for treatment of psoriasis. Int J Pharma Investig 2011; 1: 139-147.

9. Nazarenko V, Nych A, Lev B. Crystal structure in nematic emulsion. Phys Rev Lett 2001; 87: 75504-75508.

10. Alam MS, Baboota S, Ali MS, Ali M, Alam N, Alam MI, Ali J. Accelerated stability testing of betamethasone dipropionate. Int J Pharm Pharm Sci 2012; 4(4): 371 374.

11. Batavia R, Taylor KMG, Craig DQM, Thomas M. The measurement of beclomethasone dipropionate entrapment in liposomes: a comparison of a microscope and an HPLC method. Int J Pharm 2001; 212(1): 109-119.

12. Lovelyn C, Attama AA. Current State of Nanoemulsions in Drug Delivery. J Biomater Nanobiotechnol 2011; 2: 626-639.

13. Shafiq S, Faiyaz S, Sushma T, Ahmad FJ, Khar RK, Ali M. Development and bioavailability assess-ment of ramipril nanoemulsion formulation. Eur J Pharm Biopharm 2007; 66(2): 227-243.

14. Glass $B D$, Haywood A. Stability considerations in liquid dosage forms extemporaneously prepared from commercially available products. J Pharm Pharm Sci 2006; 9(3): 398-426. 